\title{
Principals and Professional Learning Communities: Breaking Down Barriers to Effective Response to Intervention in Secondary Schools
}

\author{
Danielle DiMarco* \\ School of Education, St. John's University, 8000 Utopia Parkway, New York 11439, United States \\ E-mail: danielle.dimarco1@gmail.com \\ E. Francine Guastello \\ School of Education, St. John's University, 8000 Utopia Parkway, New York 11439, United States \\ E-mail: drfrang@aol.com
}

\begin{abstract}
In the past decade, there has been a call for reform to improve adolescent literacy achievement. Response to Intervention (RTI) is a widely employed multi-tiered intervention system designed to identify and support the academic needs of at-risk students. Despite the success of RTI for younger students, there is little research documenting ways to effectively implement the model in secondary schools. This article identifies barriers that interfere with RTI implementation and highlights strategies to avoid failure. In particular, we emphasize the need for administrative support when initiating RTI and suggest building Professional Learning Communities (PLCs) to ensure teachers are offered the time to collaborate on planning, implementing, and assessing the effects of RTI. Keywords: administration, differentiated instruction, literacy, professional development, secondary education, special education
\end{abstract}

DOI: $10.7176 / \mathrm{JEP} / 12-23-03$

Publication date:August $31^{\text {st }} 2021$

\section{Introduction}

Response to Intervention (RTI) has become one of the most widely adopted intervention systems in the U.S. (Mahdavi \& Beebe-Frankenberger, 2009; Burns et al., 2013; Robinson, Bursuck \& Sinclair, 2013). RTI is not a new initiative; it has been utilized for some time (Epler, 2013; Preston et al., 2016; Raagas, 2021). According to Epler (2013) "RTI has been available for school districts to use for more than 30 years under such names as the Teacher Assistance Team Model, Pre-referral Intervention Model, Mainstream Assistance Team Model, Schoolbased Consultation Team Model, and Problem-Solving Model" (p. 1089). However, it has become more prevalent in schools since 2004 when Congress reauthorized the Individuals With Disabilities Education Act (IDEA) (Burns, 2013; Epler, 2013; Isbell \& Szabo, 2014; Samuels, 2009; Stuart \& Rinaldi, 2009).

Martin (2007) and Wedl (2005) as cited by Epler (2013) explain RTI was originally created by researchers to "eliminate the discrepancy model and have students obtain academic assistance at a much quicker pace" (p. 1089). Today, Response to Intervention (RTI) is best defined as a multi-tiered intervention system designed to promote a student-centered framework that identifies students considered at-risk for poor academic performance (Burns et al., 2013; Epler, 2013; Isbell \& Szabo, 2014; Thomas et al., 2020). According to Stuart and Rinaldi (2009) RTI "addresses the academic needs of all students by using evidence-based instructional practice, progress monitoring, and data-informed instructional problem-solving" (p. 52). All students have the right to receive this intervention from teachers qualified to provide instruction in first and second language acquisition as well as literacy development.

Implementing RTI has promoted positive outcomes such as increasing student achievement and decreasing the large number of students previously referred for special education services (Epler, 2013; Stuart \& Rinaldi, 2009). Improved instruction via research-based methods and assessments within general education classrooms has also reduced "the number of students that are over-represented in special education, such as students living below the poverty line or students whose first language is not English" (Epler, 1013, p. 1089). Professionals need to provide effective instructional opportunities for all learners, with an emphasis on supporting an increasing population of second language learners.

Researchers agree that although RTI has been widely adopted and has proven to be an effective intervention, there are challenges that interfere with its success (Burns et al., 2013; Epler, 2013; Mahdavi \& BeebeFrankenberger, 2009; Robinson et al., 2013; Thomas et al., 2020). According to Johnson and Smith (2008) "the RTI concept for older students as well, scant research and few, if any, RTI models appropriate for secondary schools exist" (p. 46). While the need for research related to RTI in middle and high schools has been identified for years, the lack of attention to this topic within these settings continues today (Johnson \& Smith, 2008; Kressler \& Cavendish, 2019; Samuels, 2009; Thomas et al., 2020). In what follows, we report the challenges 
secondary schools face as they implement RTI and offer simple strategies to avoid barriers that may interfere with its success.

\section{Challenges}

Although implementing Response to Intervention (RTI) has been viewed positively as an intervention system, it has faced challenges. Robinson et al. (2013) describe how RTI has been implemented differently across school settings stating "unfortunately, at a time when interest in RTI is high nationwide, a precise blueprint for implementing it does not exist" (p. 9). Therefore, the overall impact of RTI may lack social validity if there is no fidelity of implementation because there is no process to follow.

Similarly, Burns et al. (2013) explain that the validity of RTI models is threatened when the fidelity of implementation is not frequently assessed (p. 81). The researchers suggest that assessment of fidelity should be utilized equally in all tiers (Burns et al., 2013, p. 81). Overall, researchers appear to agree that the uncertainty surrounding the precise implementation of RTI contributes to the hesitation to utilize it over traditional intervention methods (Bartholomew \& De Jong, 2017; Burns et al., 2013; Raagas, 2021; Robinson et al., 2013).

Challenges to implementing RTI in naturalistic school settings have been identified by Cavendish et al. (2016). Using a grounded theory approach, the researchers found school personnel struggled with implementation because they were "unclear about the purpose of RTI" and were concerned, specifically, about ways systems change impacts their roles and how they are held accountable (Cavendish et al., 2016, p. 28). These findings are aligned with Talbert's (2009) view of a bureaucratic approach to systems change that leads to negative teacher responses such as resistance and anxiety (p. 563).

Foster-Fishman et al. (2007) as cited by Burns et al. (2013) define systems change as an "intentional process designed to alter the status quo by shifting and realigning the form and function of a targeted system" ( $p$. 81). Researchers appear to agree that when the purpose of a systems change is unclear and the implementers perceive the change as a bureaucratic approach, it is less accepted. According to Mahdavi and BeebeFrankenberger (2009) "acceptability supports implementation fidelity, which leads to socially important outcomes" (p. 65). Therefore, without acceptance, the social validity of RTI is once again, compromised.

Although Response to Intervention has been understudied in secondary schools (Isbell \& Szabo, 2014; Johnson \& Smith, 2008; King \& Lemons, 2014; Samuels, 2009) there is some research available identifying challenges for RTI implementation within middle and high schools (Bartholomew \& De Jong, 2017; Epler, 2013; Isbell \& Szabo, 2014; King \& Lemons, 2014; Raagas, 2021; Samuels, 2009). In 2009, Epler (2013) examined how RTI was implemented in two secondary schools located in northeastern Ohio. Although the findings of the study were favorable, it appears as though avoiding certain obstacles was a key component to RTI success at the participating sites. Epler (2013) credits Duffy (2007) for identifying challenges secondary schools may face when implementing RTI. These challenges include:

- locating age appropriate universal screening and progress monitoring tools;

- trying to find age-appropriate interventions to work in more than one academic content area;

- creating a structure that is culturally diverse;

- requiring general and special education teachers to collaborate and possibly co-teach;

- locating and utilizing research-based instruction strategies in all content areas;

- finding time to collaborate with teachers within and outside of the department they teach in;

- receiving sufficient professional development to support the implementation and maintenance of RTI;

- $\quad$ having limited parental involvement (Epler, 2013, p. 1090).

Samuels (2009) emphasizes the importance of acknowledging how any intervention faces the additional challenge of overcoming social and behavioral issues high school students may have. Additionally, Samuels (2009) explains how progress monitoring and the task of integrating content area subjects such as social studies and science have also been identified as trouble spots that impede RTI success. Finding sufficient time to collaborate was also found to pose a problem for already busy high school teachers (Epler, 2013; Samuels, 2009). In 2017, Bartholomew and De Jong (2017) identified barriers to implementing RTI in secondary schools. Interviews with secondary school principals revealed lack of knowledge of the RTI model and lack of training to implement the model interfered with RTI success (Bartholomew \& De Jong, 2017, p. 5).

\section{What Works? Features of Successful RTI in Secondary Schools}

To combat challenges associated with utilizing RTI, it may be beneficial to focus on and adopt the features of successful RTI models to guide the implementation and maintenance of this intervention. Epler (2013) identified the following components that must be set in place for RTI success in secondary schools:

- $\quad$ school administration must support the concept of RTI without trepidation and must advocate for the implementation of scientific research-based instruction;

- $\quad$ established universal screening agenda and recurrent progress monitoring must be in place; 
- teachers and administrators must be trained to collaboratively problem-solve via the collection, implementation, and monitoring of the data through the use of curriculum-based measurement assessments that will determine if adequate progress is being made;

- continuous professional development must be in place to ensure that instructional staff and administrators are maintaining a level of integrity so that the data collected are validated and the students' progress is recorded efficiently and is easily accessible to all stakeholders;

- a plan must be set in place to evaluate the RTI model for effectiveness (p. 1092).

Burns et al. (2013) add that teacher acceptance or "buy-in" is also crucial to the

success of RTI (p. 81). They advise that teacher values and experience at a potential RTI site should be studied prior to implementation and once those elements are identified, they should serve as the foundation RTI is built on (Burns et al., 2013, p. 81). Further, ongoing professional development was highlighted as a key component of RTI success (Alahmari, 2019; Burns et al., 2013; King \& Lemons, 2014).

Preston et al. (2017) highlight the findings of the National Association of State Directors of Special Education (NASDSE) stating:

educators are more likely to change their perceptions or increase buy-in with RTI when they are provided with professional development that puts changes within the historical context of RTI, shows the connection of RTI to positive student outcomes, and is combined with an increase in teachers' perceptions of their skill level and administrative support (p. 173).

Mahdavi and Beebe-Frankenberger (2009) examined two successful secondary schools implementing RTI. Overall, the researchers were able to conclude that professional development for both teachers and administrators is crucial to the success of RTI. They highlight the need for significant work time and collaboration within and across school communities to meet RTI goals (Mahdavi \& Beebe-Frankenberger, 2009, p. 71). Additionally, the authors suggest the use of fidelity checklists to support educators' intentions to implement the intervention as intended (Mahdavi \& Beebe-Frankenberger, 2009, p. 71).

\section{Professional Learning Communities (PLCs)}

Professional learning communities (PLCs) have been viewed positively in terms of providing the support necessary for successful RTI implementation. PLCs are defined as a place "teachers work together and engage in continual dialogue to examine their practice and student performance and to develop and implement more effective instructional practices" (Darling-Hammond \& Richardson, 2009, p. 49). Hord (2009), one of the leading researchers focusing her studies on professional learning communities for decades, suggests six elements community members need to implement for success; (1) community membership, (2) leadership, (3) time for learning, (4) space for learning, (5) data use, and (6) shared leadership (p. 42). These elements are aligned with the principles guiding RTI implementation and will likely support teacher-participants' understanding of their roles when asked to collaborate for RTI success. Burns et al. (2013) credits the creation on PLCs for the success of maintaining RTIs in secondary settings (p. 85).

\section{How can administrators support RTIs and professional learning?}

Isbell and Szabo (2014) examined secondary teachers' attitudes toward implementing RTI in their general education classrooms (p. 11). The researchers suggest administrators who provide training and resources while communicating purposefully about RTI and offer to support the development of collaboration through learning communities will lead to RTI success (Isbell \& Szabo, 2014, p.20). Mahdavi and Beebe-Frankenberger (2009) highlight the success of two schools in Montana piloting RTI because of their ability to collaborate effectively within their school communities. Their findings conclude how "administrative support and leadership are absolutely essential when initiating systems change as comprehensive as RTI" (Mahdavi \& BeebeFrankenberger, 2009, p. 71). Echoing Isbell and Szabo (2014) the researchers emphasize the importance of administrative support.

Aside from administrative support and collaboration, sustained professional development has been identified as a key component of RTI success (Burns et al., 2013; Epler, 2013; Isbell \& Szabo, 2014; King \& Lemons, 2014; Mahdavi \& Beebe-Frankenberger, 2009; Samuels, 2009; Stuart \& Rinaldi, 2009). PLCs are a widely adopted form of professional development because they offer sustained support and promote collaboration. Therefore, it may be essential to consider the development of a PLC in a school prior to RTI implementation.

Although teachers are agents of instruction and change facilitating student learning, it is the principal who is the crucial factor in the success of PLCs (Schmoker, 2006). Principals must create and support conditions in their schools that promote learning. This is achieved by improving the teaching and learning process. For a PLC to be effective, principals and teachers must have a shared, agreed-upon vision with specific goals for student learning, (DuFour, 2006). Additionally, principals must have an in-depth knowledge of and be involved in curriculum and instructional design as well as assessment. As the school leader, principals must be immersed in analyzing data, 
exploring research-based instructional strategies and resources, and studying academic outcomes (Roberts \& Pruitt, 2003). Further, principals support PLCs by providing the flexibility to make adjustments and modify schedules and procedures allowing PLCs to function.

Principals as educational leaders must create and sustain the learning environment by providing materials and resources, including human resources to support the PLC. Since most PLCs occur during the workday, it is the responsibility of principals to provide time and a location to meet that is free of distraction (Mullen \& Hutinger, 2008). Ultimately, the success of a PLC is contingent on a principal's ability to serve as a catalyst in building a culture of learning for teachers and subsequently, for students (Mitchell \& Sackney, 2006).

\section{Lessons Learned and Future Research}

The research reviewed for this paper offers implications for the successful implementation of RTI in secondary school settings. We urge policy makers and administrators to consider the importance of dedicating time to preview potential secondary school sites prior to RTI implementation in order to determine whether or not the intervention will be accepted by those implementing it. In addition, examining a potential site to identify levels of teacher experience will help to determine the starting point or foundation RTI will build upon. Although limited, existing research has emphasized the importance of supportive administrators and adopting the PLC model as solutions to providing ongoing professional development and offering the collaborative structure necessary for RTI success in secondary schools.

Future researchers should consider exploring the success of RTI models in secondary schools where a PLC is either about to be launched or existing. To ensure educators are motivated to successfully implement RTI, we suggest researchers collect preliminary data related to teachers' attitudes towards RTI and their willingness to learn about the RTI model. Data sources should focus on teacher and administrator perceptions related to implementing RTI with the support of a PLC. Lastly, we believe researchers should also consider employing a comparative study to determine the success of RTI in secondary settings where administrators receive RTI training prior to implementing the model compared to administrators that receive no training.

\section{Conclusion}

Research related to implementing RTI within secondary schools is limited. Therefore, additional research to determine the structure and components that will best support RTI in a secondary setting is still needed. An indepth analysis of specific guidelines that best support the implementation and maintenance of a PLC intended to support RTI in secondary school settings may also be valuable to teachers, administrators, and policy makers considering the adoption of RTI at their school site.

\section{References}

Alahmari, A. (2019). A review and synthesis of the response to intervention (RTI) Llterature: Teachers' implementations and perceptions. International Journal of Special Education, 33(4), 894-909.

Bartholomew, M., \& De Jong, D. (2017). Barriers to implementing the response to intervention framework in secondary schools: Interviews with secondary principals. NASSP Bulletin, 101(4), 261-277.

Burns, M.K., Egan, A.M., Kunkel, A.K., McComas, J., Peterson, M.M., Rahn, N.L., \& Wilson, J. (2013). Training for generalization and maintenance in RTI implementation: Front-loading for sustainability. Learning Disabilities Research \& Practice, 28(2), 81-88.

Cavendish, W., Harry, B., Menda, A.M., Espinosa, A., Mahotier, M. (2016). Implementing response to intervention: Challenges of diversity and system change in a high-stakes environment. Teachers College Record, 118, 1-36.

Darling-Hammond, L., \& Richardson, N. (2009). Teacher learning: What matters? Educational Leadership, 66(5), 46-53.

DuFour, R. (2006). Collaboration is the key to unlocking potential, The Learning Principal, 2(3), 6-7.

Duffy, H. (2007) Meeting the needs of significantly struggling learners in high school: A look at approaches to tiered instruction. National High School Center.

Epler. P. (2013). Using the response to intervention (RTI) service delivery model in middle and high schools. International Journal for Cross-Disciplinary Subjects in Education. 4(1). 1089-1098.

Foster-Fishman, P.G., Nowell, B., \& Yang, H. (2007) Putting the system back into systems change: A framework for understanding and changing organizational and community systems. American Journal of Community Psychology, 39, 197-215.

Hord, S.M. (2009). Professional learning communities: Educators work together toward a shared purpose. Journal of Staff Development, 30(1), 40-43.

Isbell, L.J., Szabo, S. (2014). Understanding secondary teachers'concerns about RTI: Purposeful professional communication. International Journal for Professional Educators, 11.

Johnson, E. S., \& Smith, L. (2008). Implementation of response to intervention at middle school: Challenges and 
potential benefits. Teaching Exceptional Children, 40(3), 46.

King, S.A., \& Lemons, C.J. (2014). Response-to-Intervention at the secondary and elementary level: An exploratory survey of educators. Learning Disabilities: A Mutidisciplinary Journal, 20(4), 189-200.

Kressler, B., \& Cavendish, W. (2020). High school teachers' sense-making of response to intervention: A critical practice analysis. Education and Urban Society, 52(3), 433-458.

Mahdavi, J.N., \& Beebe-Frankenberger, M.E. (2009). Pioneering RTI systems that work: Social validity, collaboration, and context. Teaching Exceptional Children, 42(2), 52.

Mitchell, C., \& Sackney, L. (2006). Building schools, building people: The school principal's role in leading a learning community. Journal of School Leadership, 16(5), 627-640.

Mullen, C.A., \& Hutinger, J.L. (2008). The Principal's role in fostering collaborative communities through faculty study group development. Theory Into Practice, 47(4), 276-285.

Preston, A. I., Wood, C. L., \& Stecker, P. M. (2016). Response to intervention: Where it came from and where it's going. Preventing School Failure: Alternative Education for Children and Youth, 60(3), 173-182.

Raagas, M. J. R. (2021). Alignment of school and leadership pactices in basic education with response-tointervention model. European Journal of Education and Pedagogy, 2(3), 207-211.

Roberts, S. M., \& Pruitt, E. Z. (2003). Schools as professional learning communities. The Learning Principal. $2(6), 6-7$.

Robinson, G.G., Bursuck, W.D., \& Sinclair, K.D. (2013). Implementing RTI in two rural elementary schools: Encouraging beginnings and challenges for the future. The Rural Educator, 34(3).

Samuels, C.A. (2009). High schools try out RTI. Education Week, 28(19), 20-22.

Schmoker, M. (2006). Results now: How can we achieve unprecedented improvements in teaching and learning. Alexandria, VA: Association for Supervision and Curriculum Development.

Stuart, S.K., \& Rinaldi, C. (2009). A collaborative planning framework for teachers implementing tiered instruction. Teaching Exceptional Children, 42(2), 52.

Talbert, J.E., (2009). Professional learning communities at the crossroads: How systems hinder or engender change. In A. Hargraves, A. Lieberman, M. Fullan \& P. Hopkins (Eds.) Second International Handbook of Educational Change. 555-571. Springer, Netherlands.

Thomas, C. N., Allen, A. A., Ciullo, S., Lembke, E. S., Billingsley, G., Goodwin, M., \& Judd, L. (2020). Exploring the perceptions of middle school teachers regarding response to intervention struggling readers. Exceptionality, 1-18. 